\title{
Family Planning Programs in the Third World
}

\author{
$B y$ RONALD FREEDMAN
}

\begin{abstract}
Most of the population of less developed countries (LDCs) now lives in countries with national family planning programs to reduce fertility and improve family welfare. Such programs are a new phenomenon. In some LDCs increasing birth-control practice and fertility declines occurred along with considerable social and economic development, but even there rapid changes among the disadvantaged masses are generally associated with strong family planning programs. Fertility has also fallen in some countries with only some development but with vigorous family planning programs. China, Indonesia, Sri Lanka, and Thailand are such cases. In such places as sub-Saharan Africa and South Asia, fertility generally remains quite high, apparently because of little development and traditional familial institutions. Even in these situations, however, there are examples of significant fertility declines, in some cases nationally and in other cases in intensive, high-quality pilot projects that have established the latent demand for family planning.
\end{abstract}

Ronald Freedman is professor emeritus of sociology at the University of Michigan, where he received B.A. and M.A. degrees, followed by a Ph.D. at the University of Chicago. During 41 years at Michigan he founded the Population Studies Center. His career has involved teaching, research, and consultation about fertility and family planning in both developed and less developed countries, including Taiwan, China, Hong Kong, Indonesia, and Malaysia. He is past president of the Population Association of America. 
$\mathrm{B}^{\mathrm{Y}}$ 1983, 76 percent of the population of less developed countries (LDCs) lived in countries with official policies and national family planning programs to reduce their population growth by reducing fertility. ${ }^{1}$ An additional 17 percent lived in countries that officially supported family planning programs to improve the health and welfare of their mothers and children.

Such national policies and family planning programs are a new phenomenon. In 1960 only one country, India, had such a program and that was ineffectual. At that time probably less than 10 percent of the married women of childbearing age in LDCs were using contraception and much of that practice was ineffective. By 1985 an estimated 45 percent - about 400 million women -were using contraception, and 80 percent of that practice involved such effective methods as the contraceptive pill, the intrauterine device (IUD), and sterilization. The most widely used method in LDCs, as in the world as a whole, is now sterilization. ${ }^{2}$

These massive increases in contraceptive prevalence in just a few decades are remarkable, because they have required profound changes in reproductive behavior deeply rooted in traditional familial institutions and in values about intimate sexual relationships. Although these changes are impressive, further large increases in contraceptive use in LDCs are necessary if LDC fertility is to reach the low levels required by the population policies of most

1. Dorothy L. Nortman, Population and Family Planning Programs: A Compendium of Data through 1983 (New York: Population Council, 1985), p. 32.

2. United Nations, Levels and Trends of Contraceptive Use as Assessed in 1988 (New York: United Nations, 1989). Unless otherwise indicated, contraceptive prevalence rates are from this source.
LDC countries and the population projections of the United Nations.

While the contraceptive prevalence rates were rising in LDCs between 1960-65 and 1980-85, the fertility rates were falling, partly because of rising age at marriage but mainly because of deliberate fertility limitation within marriage. The total fertility rate fell from 6.1 to 4.2 , a 31 percent decline. $^{3}$

Despite the decline in fertility, the decline in the rate of population growth in LDCs as a whole has been small, because there was a simultaneous decline in mortality, which largely offset the fertility decline.

The contraceptive prevalence rates cited for all LDCs are weighted averages of widely varying country rates. The rates are moderately to very high in all of East Asia and in parts of Southeast Asia - over 65 percent in China, Hong Kong, Singapore, Korea, and Taiwan and close to 50 percent in Indonesia. In Latin America the overall rate is 54 percent, with especially high rates in Brazil, Mexico, Colombia, and Costa Rica, moderate rates -40 to 60 percent - in most other countries, but a rate as low as 7 percent in Haiti. The prevalence rates are almost uniformly low and fertility rates very high in sub-Saharan Africa and in much of the Islamic population of the Near East and Southwest Asia. Even in these regions, where conditions for fertility decline are believed to be very unfavorable, exceptions are beginning to appear. There have been significant increases in contraceptive use and declines in fertility

3. United Nations, World Population Prospects, 1988 (New York: United Nations, 1989), p. 150. The total fertility rate estimates the number of children each woman would have if she lived through the childbearing years, subject to fertility rates at each childbearing age for the specified year. 
in Zimbabwe, Botswana, and Kenya recently. ${ }^{4}$ In the Muslim world there are similar examples in Tunisia, Algeria, Egypt, ${ }^{5}$ and in some fundamentalist Islamic regions of Indonesia.

\section{CAUSES OF THE RISE IN CONTRACEPTIVE PREVALENCE}

The causes of such variability in contraceptive use and fertility levels are matters of controversy.

Twenty-five years ago, based on the rapid fertility decline in the West between about 1870 and World War II, most scholars believed that the answer was simple. Social and economic development, urbanization, higher educational levels, work in the modern, nonfamilial economy, and lower mortality increased the cost and decreased the benefits of children. They also increased the value of investing more in a smaller number of children, so that small families planned with the use of contraception became the norm. There is an important element of truth in these ideas. When social and economic development levels are high, small families and birth control are widely prevalent.

In recent decades, however, empirical studies have indicated that explaining the causes of the transition from high to low fertility is not so simple. Historical studies have demonstrated that fertility decline began in various parts of Europe under widely varying social and economic conditions and without modern contraceptives or

4. Data about recent levels of contraceptive practice and fertility in this article for the following countries are from the ongoing surveys of the Demographic and Health Surveys, Institute for Resource Development, Columbia, MD: Botswana, Burundi, Indonesia, Kenya, Liberia, Mali, Senegal, Thailand, Togo, and Zimbabwe.

5. Philippe Fargues, "La baisse de la fécondité arabe," Population, 43(6):987 (Nov.-Dec. 1988). family planning programs. ${ }^{6}$ Whether fertility did decline was also considerably influenced by such cultural factors as secularism, language, and ethnicity.

A growing body of evidence from the experience of LDCs since 1960 also indicates that the adoption of birth control and fertility declines occur under a variety of conditions. Massive changes in reproductive behavior appear to be influenced not only by the changing demand for children and for family planning methods but also in some cases by the supply of birth-control services and information, by both organized programs and the private sector.

The World Fertility Survey in 42 LDCs found that such structural variables as education, labor force activity, and urbanization have only modest relations to contraceptive use and fertility across Third World countries. Further, the relationships that do exist vary greatly between the regions of the world. ${ }^{7}$

A hypothesis receiving increasing attention is that diffusion of ideas about the concept, means, prevalence, and legitimacy of birth control plays an important role in fertility decline. This ideational factor may be particularly important for present-day LDCs, because the earlier development and practice of these ideas in the West is part of world history and is carried by the international mass-media network. Spreading this set of ideas is an essential function of family planning programs.

6. For example, Ansley J. Coale and Susan C. Watkins, eds., The Decline of Fertility in Europe (Princeton, NJ: Princeton University Press, 1986).

7. German Rodriguez and John Cleland, "Socio-Economic Determinants of Marital Fertility in 20 Countries: A Multivariate Analysis," in World Fertility Survey Conference, 1980: Record of Proceedings (London: World Fertility Survey, 1981), 2:337403. 
Fertility declines in LDCs do not always involve organized national family planning programs. Notable fertility declines in Latin America - for example, in Brazil have occurred with the assistance of private organizations or individual contacts with pharmacies and doctors.

A variety of studies have attempted to determine the extent to which family planning programs have produced fertility declines in addition to what would have happened anyway as a result of social and economic development. For example, Lapham and Mauldin, in a study of $\mathbf{9 3}$ LDCs, reported that socioeconomic development and family planning program effort each had an independent effect on contraceptive use and fertility decline. But the major reported effect was a joint product of the two forces. ${ }^{8}$

It is illustrative of the problems in such attempts at a comprehensive answer that this one has been criticized on the grounds, among others, that countries that already have declining fertility mount strong programs that are, then, more the effect than the cause of the fertility decline.

The issue is complicated by the fact that countries with little social and economic development generally have very weak family planning programs, presumably because they do not have the infrastructure required for this or other development programs. All the 22 countries ranked lowest on socioeconomic development indices in the Lapham-Mauldin study are also ranked as having weak or very weak family planning programs.

8. Robert J. Lapham and W. Parker Mauldin, "The Effects of Family Planning on Fertility: Research Findings," in Organizing for Effective Family Planning Programs, ed. R. J. Lapham and G. B. Simmons (Washington, DC: National Academy Press, 1987), pp. 647-80.
I believe that, on balance, the evidence is that family planning programs can have an effect that is interdependent with, but not merely reflective of, social and economic development. There is, however, no firm consensus among scholars in the population field on this important issue.

Since a simple cross-cultural explanation of all LDCs still escapes us, it may be the better part of wisdom to consider groups of countries with common elements.

I will be referring to effective family planning programs - those that are successful in enabling large numbers of couples to have the number of children they want when they want them. For countries that have a policy to reduce the rate of population growth, an effective program also motivates enough couples to limit family size so that national fertility rates fall. This may involve education, massmedia programs, various types of incentives, and social and political pressure. Such activist programs to change values and behavior are sometimes controversial both within the countries and in the world arena.

\section{LDCs WITH RAPID DEVELOPMENT}

Fertility rates certainly have fallen especially rapidly in countries with considerable social and economic development as well as effective family planning programs - Korea, Taiwan, Singapore, and Mexico are examples. It is probable that in the long run fertility would have fallen in such countries with or without family planning programs. It is doubtful, however, that the decline would have been as rapid without the family planning programs, especially among the disadvantaged masses the poor, the uneducated, and the rural. 
For example, consider the case of Taiwan, a pioneer in both family planning and other development programs. ${ }^{9}$ In 1960, just before the program was begun, the total fertility rate was about 6 and contraceptive use was still at low levels. By 1986, only 26 years later, the fertility rate had fallen by 70 percent to 1.7 -below replacement levels - and virtually all women were using contraception before the end of their childbearing years. The level of contraceptive use doubled from 28 to 56 percent between 1965 and 1970. More important, among illiterate women contraceptive use during this period increased from 19 to 51 percent. By 1975, the differentials in contraceptive use between strata defined by education, urbanization, or income had virtually disappeared. No doubt the success of Taiwan's program was interdependent with its rapid social and economic development, but it is unlikely that the disadvantaged masses - the poor, rural, and illiterate would have adopted family planning so rapidly without the family planning program. Even in 1985, 60 percent of Taiwanese couples were getting their contraceptive services through the government programs.

Taiwan also illustrates the fact that a rapid change in reproductive behavior can occur despite persistence of traditional familial institutions. Even in 1985, when fertility was very low and contraceptive prevalence very high, a large majority of older Taiwanese were living with married sons and about two-thirds of recently married

9. Ming-Cheng Chang, Ronald Freedman, and Te-Hsiung Sun, "Trends in Fertility, Family Size Preferences and Family Planning Practice: Taiwan, 196185," Studies in Family Planning, 18(6):320-37 (Nov.Dec. 1987). couples began married life living with the husbands' parents. ${ }^{10}$

The sharp fertility reduction in the West before World War II, without either modern contraceptives or organized programs, often is cited as evidence that those are unnecessary for fertility decline if development is sufficient. It is plausible, however, that, had organized programs with modem contraceptives been available in Europe, fertility might have fallen more rapidly, more equally among social groups, and with less suffering from unwanted births and abortions.

\section{COUNTRIES WITH MODERATE DEVELOPMENT}

There is another group of countries in which some social and economic conditions were considered to be unfavorable prior to their programs and fertility declines.

The most conspicuous example is China, where fertility declines of unprecedented magnitude and speed have occurred under presumably unfavorable social and economic conditions but with a massive family planning program of awesome effectiveness. Between 1970, when the rural family planning program began in earnest, and 1980 the fertility rate of rural China fell from 6.3 to 2.9 , a 53 percent decline. For rural illiterate women, fertility fell by 50 percent, from 6.6 for the years $1967-70$ to 3.3 for $1979-82$. China's fertility program is unprecedented for its massive apparatus and effectiveness. It depends on the ability of the government to mobilize and control the behavior of the masses at the village

10. Maxine Weinstein et al., "Household Composition, Extended Kinship, and Reproduction in Taiwan: 1965-1985," Population Studies, in press. 
level, all the more temarkable because of the hundreds of thousands of villages involved, with 800 million rural people distributed over a vast area. No doubt, remarkable preceding reductions in mortality and more modest but significant gains in education and other social changes are relevant. The close connection in the timing of the sharp fertility decline and the onset of the rural program and its simultaneous occurrence in all major sectors of the population make it highly probable, however, that the program was a major force in the rapid decline.

Questions can be raised about degrees of coercion in the Chinese program. Nevertheless, it is important and unexpected that a program could mobilize the infrastructure, bureaucratic apparatus, and the masses of the population to produce such a large and rapid fertility decline. The absence of such capacity in such countries as India, Bangladesh, and Pakistan may account in part for the ineffectiveness of their family planning programs.

Indonesia's fertility decline and its rise in contraceptive prevalence also has occurred under initially rather unfavorable social and economic conditions. Contraceptive prevalence rates have risen from about 2 percent, when the program began in 1970 , to 48 percent in 1987. During the same period, fertility fell from an estimated 5.5, during the years $1967-70$, to 3.3. Like China, Indonesia has utilized its longstanding institutional capacity to mobilize the village masses for its family planning programs, where the traditional authority of the village leader and organized peer pressure have played an important role. Warwick, in an intensive study of Indonesia's program, has made a convincing case that its distinctive program strategy and aggressive implementation have had a major independent effect that cannot be accounted for by the significant social and economic development gains that have also occurred there since $1970 .^{11}$

Thailand is another country whose rapid fertility decline to very low levels and increasing contraceptive prevalence to high levels have occurred with a very strong program and only moderately favorable socioeconomic conditions. ${ }^{12}$

In the Indian state of Kerala and in Sri Lanka, improvements in health, education, and minimal subsistence supports have been associated with lower fertility levels and moderately high contraceptive prevalence, despite low and lagging levels of economic development. In both cases increasing age at marriage has had a role in fertility decline.

\section{COUNTRIES WITH RELATIVELY LTTLE DEVELOPMENT}

Finally, we consider places with little socioeconomic development and weak infrastructure, where individuals still receive most of their physical and emotional support from familial institutions and where children are perceived to yield significant benefits as compared to their costs. The status of women is poor and often depends on their fertility. Most of the countries of sub-Saharan Africa are in this category, along with India, Pakistan, Bangladesh,

11. Donald P. Warwick, "The Indonesian Family Planning Program: Government Influence and Client Choice," Population and Development Review, 12(3):453-90 (Sept. 1986).

12. John Knodel, Aphichat Chamratrithirong, and Nibhon Debavalya, Thailand's Reproductive Revolution: Rapid Fertility Decline in a Third-World Setting (Madison: University of Wisconsin Press, 1987). 
and smaller countries of Southwest Asia. The countries in this group that have family planning programs have not been very successful in increasing contraceptive prevalence enough to decrease fertility very much.

Low contraceptive prevalence and high fertility in such countries are generally explained on the ground that having many children, and especially sons, is regarded as a positive good. The question of demand for fertility control simply does not arise for most families. According to this view, family planning programs are inevitably ineffective in these places, because there is no significant demand for their services.

On the other hand, advocates of the potential of family planning programs argue that in many such countries there is at least some latent demand for family planning services, but that it does not become manifest because the family planning system is weak, with poor-quality services provided in ways that are inappropriate for the local culture.

The largest among these countries, India, with more than 800 million people, is important not only because of its size but also because it has had a family planning program for decades and has given it high priority at least since 1966 . Although neither its fertility nor family planning data are of good quality, a probable consensus among informed observers is that there has been a modest rise in contraceptive prevalence and a comparably modest fall in fertility, especially in the last 15 years. According to estimates of the Indian Department of Family Planning, contraceptive prevalence rose from 4 percent in 1967 to 38 percent in 1987. Variation in such contraceptive prevalence rates between 352 districts, including most of India's population, has been shown to be modestly correlated to female literacy and rural electrifi- cation, but its relation to family planning program effort is unknown.

India's program has gone through many permutations in the last twenty years. This, together with the great variation in cultural, caste, economic, and social strata in this vast country, makes it difficult to summarize the program's problems. Nevertheless, there probably is a consensus among most Indian and foreign observers that the program has been poorly executed. ${ }^{13}$ One Indian official some years ago told me, "The Indian program hasn't failed. It hasn't been carried out."

The program has been criticized for:

- an obsession with targets for the program and for each worker set at such high levels and so obviously unattainable as to demoralize personnel;

- too much concentration on one drastic method - sterilization - linked to a controversial incentive program;

- rotating its district family planning and other officers among posts so often as to impede continuity in a long-run program; and

- the fact that officials at central and state and even district levels are not in touch with the realities of life at the village level, unlike the cases of Indonesia and China, which countries use ties to those grass-roots levels very effectively.

On the positive side is the fact that 72 districts are reported to have contraceptive prevalence rates of 50 percent or higher and 18 have rates of 60 percent or more.

13. In an address to a meeting of the International Union for the Scientific Study of Population in New Delhi in September 1989, Prime Minister Rajiv Gandhi admitted that the Indian program has fallen far short of aspirations because of bureaucratic bungling and inflexibility in the face of large local variations in the social situation. 
Even if discounted for overreporting, these data suggest that some combination of favorable conditions and possibly better program implementation are found in some districts, which might provide models for other districts.

Unfortunately, despite India's considerable intellectual and scientific resources, there has been no sustained effort to learn what combination of specific developmental and cultural conditions, program design, and program implementation can account for these successes or for India's failure to be more generally successful in attaining its own goals for its population program.

Pakistan, with 115 million people, has a very low contraceptive rate, recently estimated at only 9 percent, and a fertility rate of about 6. Although it has had a family planning program for several decades, it has been a low-priority, poorly implemented program. The combination of low levels of social and economic development, a patriarchal, familistic culture, religious barriers, and an ineffective family planning program makes its lack of progress toward its professed lower-fertility goals understandable.

Bangladesh, with more than 100 million people, has the low developmental levels and the cultural barriers that characterize Pakistan. While its contraceptive prevalence rate of 25 percent is significantly higher than Pakistan's and many women report wanting no more children on fertility surveys, respected observers have asserted that familial institutional supports for high fertility make early fertility declines unlikely. In Bangladesh, however, a carefully monitored pilot project in Matlab seems to have demonstrated that an intensive, highquality family planning service program can make a significant difference even in such unfavorable circumstances. ${ }^{14}$ The project brought contraceptive prevalence up from very little to 45 percent, with a commensurate fall in fertility. Attempts are now being made to extend into new areas the essentials of what was learned in Matlab. Initial results are encouraging but not conclusive.

At Chogoria, in Kenya, a medical missionary hospital mounted a family planning program with some similarities to the project in Matlab..$^{15}$ There, too, contraceptive prevalence has been brought up to the 40 percent level. Statements indicating a potential demand have been tested with a good-quality service program and found to be real.

Skeptical evaluations of the prospects for fertility decline in sub-Saharan Africa have been applied to Kenya as well. ${ }^{16}$ A recent survey in Kenya has, however, shown a significant 50 percent rise in contraceptive prevalence between 1984 and 1989 , with an accompanying fall in fertility from 7.7 to 6.7 . By 1989,40 percent of married women as young as 25-29 years old said they wanted no more children and 36 percent said that they wanted to postpone the next child for at least two years. The Chogoria test and the recent survey suggest that these statements are meaningful.

14. Michael A. Koenig et al., "Trends in Family Size Preferences and Contraceptive Use in Matlab, Bangladesh," Studies in Family Planning, 18(3):11727 (May-June 1987).

15. Howard I. Goldberg, Malcolm McNeil, and Alison Spitz, "Contraceptive Use and Fertility Decline in Chogoria, Kenya," Studies in Family Planning, 20(1):17-25 (Jan.-Feb. 1989).

16. Odile Frank and Geoffrey McNicoll, "An Interpretation of Fertility and Population Policy," Population and Development Review, 13(2):209-43 (June 1987). 
In many sub-Saharan countries the basic infrastructure is weak, and there is a severe shortage of professional personnel. Small-scale investigations, often less intensive and rigorous than the cited pilot projects, have been used to develop and test provisionally the feasibility of locally appropriate service programs. In one such program in the Sudan, contraceptive prevalence rates were reported as rising from 9 to 25 percent in eight years, and replication yielded similar results in four years. ${ }^{17}$

In many poor, high-fertility LDCs, including Bangladesh and Kenya, lower mortality means higher child survival, so that many LDC women, by the time they are about 30 , already have alive the number of children they want. The increasing number of living children in each family creates pressure on traditional institutions developed on the implicit assumption that many children would die.

At the same time, increasing numbers of Third World citizens are getting new ideas from the expanding world network of communication, transportation, and economic interdependence, whose influence increasingly reaches into even LDC villages. These ideas include new facts and models about reproductive behavior but, just as important, about health, the value of education, new consumption goods, and political power. Such new ideas generate rising aspirations among parents, both for themselves and for their children, although the pace of such changes varies enormously from place to place. The conventional wisdom has been that poor, illiterate LDC peasants are unlikely to be interested in

17. Operations Research Program, Africa: ANew Frontier in Family Planning (New York: Columbia University, Center for Population and Family Health, 1988). The term "operations research," designating rigorous quantitative work in some other fields, is less appropriate for some of these projects. birth control, but under the changing conditions induced by the greater survival of children and the impact of new ideas, that wisdom may be less generally valid than in earlier days. Anational survey in Indonesia in 1976 found unexpectedly that new contraceptive practice was considerable among the rural, the poor, the uneducated, and the residents of backward villages. ${ }^{18}$

It is in such situations that increasing numbers of women with years of childbearing still ahead are saying on surveys that they want no more children. This does not mean that they have all made definite, unambiguous decisions. Some have, but much larger numbers are under crosspressures between traditional values and institutions and new realities and ideas. $A$ good family planning information and service program helps to crystallize latent demand for contraception by emphasizing the usefulness and legitimacy of family planning as a partial solution for the problems of families.

The pilot studies at Matlab and Chogoria and declining fertility in several African countries are indications of the potential for successes in at least some places where success is believed, a priori, to be very unlikely. This does not mean, however, that high contraceptive prevalence and lower fertility can be achieved everywhere where social and cultural conditions apparently are unfavorable.

\section{PROSPECTS AND POLICIES IN POORLY DEVELOPED COUNTRIES}

There is, in fact, little doubt that traditional familial institutions, low develop-

18. Ronald Freedman, S. E. Khoo, and B. Supraptilah, "Use of Modern Contraceptives in Indonesia: A Challenge to the Conventional Wisdom," International Family Planning Perspectives, 7(1):3-15 (Mar. 1981). 
ment levels, poor infrastructure, and shortages of indigenous professional personnel and of other resources make early rapid fertility declines unlikely in places like Pakistan and much of sub-Saharan Africa. For example, surveys in 1986 and 1987 in Mali, Burundi, Liberia, Senegal, and Togo found that the number of children women wanted were, on average, similar to the number they were having - six to seven.

Under these difficult circumstances, it is particularly unpromising to attempt to implement national plans for uniform programs across a country without regard to local readiness, ethnic and tribal differences, trained personnel locally acceptable, and adequate supplies of appropriate contraceptives and other resources. It seems to be more rational to begin with selective program initiatives in promising local areas and population strata and for purposes meeting manifest local needs.

Pilot projects, such as that in Matlab, Bangladesh, or the one in Chogoria, Kenya, have the potential of testing for latent demand in local areas, identifying the subgroups that are interested, and developing culturally relevant programs to meet the demand, if demand is found. Such projects with intensive inputs may appear to be expensive, but given the poor investment return from ineffective national programs in many poor LDCs, the investment in pilot projects appears to be worthwhile. Such pilot projects should be mounted in situations where a success is likely. If the possibility of an effective program is gravely in question, it is plausible to begin under favorable conditions with later expansion to more difficult places as confidence, legitimation, and program models develop.

In surveys in sub-Saharan Africa a considerable number of women who are not interested in restricting the number of their children before having a large number say that they would like to postpone their next birth for at least two years. This suggests that the initial use of contraception for spacing rather than limiting births might find significant numbers accepting contraception, especially in the many African countries in which prolonged sexual abstinence after a birth has been customary. Some family planning programs in such countries already are moving in that direction in combination with maternal and child health services. Even if the total number of births women have remains unchanged, lengthening the intervals between births has the effect of decreasing annual fertility rates and the rate of population growth.

\section{EXTERNAL SUPPORT FROM DEVELOPED COUNTRIES}

LDCs get considerable support from developed countries and from the United Nations, the World Bank, and other private and public agencies. ${ }^{19}$ In 1985 , about $\$ 512$ million in such external support was committed. While the United States Agency for International Development has made the largest bilateral commitments, at least 16 other countries in 1985 made contributions, several of them giving more than the United States when computed as a percentage of gross national product.

In most LDCs with family planning programs, such external financial assistance has been important in providing foreign exchange for purchasing contraceptives and other supplies and equipment and has also financed such infrastructure as clinics and motor vehicles. To varying degrees

19. Dorothy L. Nortman, "External Funding for Population Programs in Developing Countries, 19821985," International Family Planning Perspectives, 14(1):2-8 (Mar. 1988). 
such support also pays for operating costs of the programs. The value of technical assistance from advisers provided by external agencies is more controversial, but there is little doubt that the external agencies have played an important role in legitimating family planning programs through dialogues with political leaders and in other ways. External assistance has sometimes been attacked or even rejected on ideological grounds.

\section{THE ROLE OF \\ UNFORESEEN SOCIAL CHANGE}

One purpose of both pilot studies and other soundings of latent demand in highfertility countries is early detection of the effects of social changes. Traditional cultural and institutional forces supporting high fertility are not immune to the rapid social changes sweeping the world. Social scientists do much better at analyzing what societies have been than what they are becoming.

Recent rises in contraceptive prevalence and declines in fertility in places like Kenya, Zimbabwe, Botswana, and Algeria were not foreseen by most observers a few years ago. Once fertility in LDCs has declined by about 10 percent with more birth control, in most cases the decline continues. This also was the earlier experience in the West.

Most observers also did not foresee in the 1960s the rapid demographic transformations of places like Taiwan, Korea, Indonesia, China, and some Latin American countries. That is because they did not foresee the scope and rapidity of the following changes, which variously affected major fertility and mortality decline: rapid social and economic development, creation of family planning programs effective in reaching large parts of the population, legitimation of the idea of birth-control methods and of organized family planning programs, and development of new birthcontrol methods.

The prospects of effective family planning programs and fertility declines in specific high-fertility countries will depend on the future scale of such changes in each country as well as on other changes not presently foreseen. 